\title{
KUALITAS LAYANAN TERPADU (TOTAL QUALITY SERVICE); DEFINISI, KONSEP DASAR DAN PANDANGAN ISLAM PADA INSTANSI PENDIDIKAN
}

\author{
Ilfan Tufail
}

Mahasiswa Jurusan Manajemen Pendidikan Islam Fakultas Agama Islam Universitas Nurul Jadid (UNUJA) Paiton Probolinggo

\section{Abstrak}

Kualitas jasa yang unggul dan konsisten dapat menumbuhkan kepuasan pelanggan yang pada akhirnya akan memberikan dampak yang konsisten dengan berbagai manfaat salah satunya loyalitas (loyality). Namun semua hal itu memerlukan waktu dan proses pemahaman untuk mengetahui karakteristik serta mengidentifikasi kebutuhan pelanggan. Konsep dasar dari TQS sendiri adalah menekankan pada bagaimana efektifitas dan efesiensi maksimalisasi pelayanan. Untuk lembaga pendidikan sebagai instansi non-profit service merupakan suatu lembaga yang memberikan layanan jasa yang dalam hal ini mempunyai empat (4) karakteristik sebagai berikut, yaitu : 1. Intangibility, 2. Inseparability, 3. Variability, 4.Perishability. Kerangka identifikasi pelanggan Instansi pendidikaan meliputi tiga unsur, yaitu:1. pelanggan internal berupa akademik dan administratif , 2. pelanggan eksternal langsung, 3. pelanggan eksternal tidak 
langsung. Islam sebagai selah satu agama juga tak luput mendikti proses Total Quality Service itu tersendiri. Dengan demikian adanya pemahaman karakteristik, identifikasi kebutuhan pelanggan Instansi pendidikaan memberikan harapan bahwa pelayanan yang diberikan akan mampu memberikan kepuasan pada pelanggan.

Kata Kunci: kualitas layanan, jasa, Instansi pendidikaan, kebutuhan, pelanggan, kepuasan, dan pandangan Islam.

\section{A. Pendahuluan}

Dewasa ini, pada era globalisasi kualitas dipandang sebagai salah satu cara atau kaifiyah untuk mencapai keunggulan kompetitif (competitive advantage), karena kualitas merupakan salah satu faktor utama yang menentukan pemikiran dan penilaian terhadap produk beserta jasa bagi konsumen. Menurut Crosby, kualitas dipandang sebagai conformance to requirment (kesesuaian pada persyaratan). Persyaratan yang dimaksud merupakan persyaratan konsumen, bukan perusahaan stsu dslsm konteks ini instansi pendidikan terkait. Dengan kata lain, kualitas merupakan keseluruhan karakteristik atau dimensi periogatif suatu jasa dan produk yang dapat memuaskan kebutuhan konsumen dan sesuai dengan persyaratan yang dikehendakinya. Kualitas bukan dimaksud disini tidak hanya terpaku atau identik dengan kemewahan dan kehebatan, karena apabila karakteristik tersebut bukan merupakan persyaratan yang 
dikehendaki konsumen, maka produk ataupun jasa tersebut tidak berlabel produk atau jasa yang berkualitas.

Kualitas jasa yang unggul dan konsisten dapat menumbuhkan kepuasan pelanggan yang pada akhirnya akan berimplikasi terhadap progresifitas dan memberikan berbagai manfaat. Tetapi, untuk memahami bagaimana mengevaluasi kualitas yang diterima oleh konsumen tidak mudah. Hal ini disebabkan kualitas jasa diciptakan melalui proses produksi dalam pabrik (instansi pendidikan) yang selanjutnya diserahkan kepada konsumen sebagaimana kualitas barang. Sebagian besar kualitas jasa dilakukan ketika proses pemberian jasa terjadi dalam proses interaksi diantara konsumen dan terdapat kontak personal dengan penyelenggara jasa tersebut.

Sehingga ketika kuliatas jasa sudah berlabel positif, maka mutu pendidikan didalam persepsi masyarakat akan bernilai positif juga, karena Secara operasional, mutu ditentukan oleh dua faktor, yaitu terpenuhinya spesifkasi yang telah ditentukan sebelumnya dan terpenuhinya spesifkasi yang diharapkan menurut tuntutan dan kebutuhan pengguna jasa. Mutu yang pertama disebut quality in fact (mutu sesungguhnya) dan yang kedua disebut quality in perception(mutupersepsi). Dalam penyelenggaraannya, quality in fact merupakan profl lulusan institusi pendidikan yang sesuai dengan kualifkasi tujuan pendidikan, yang berbentuk standar kemampuan dasar berupa kualifaksi akademik minimal yang dikuasai oleh peserta didik. Sedangkan quality in 
perception pendidikan adalah kepuasan dan bertambahnya minat pelanggan eksternal terhadap lulusan institusi pendidikan.

Sehingga tulisan ini mencoba menguraikan tentang apakah Total Quality Service (TQS) itu?, Bagaimana pandangan Islam terkait TQS tersebut? Dan bagaimana konsep dasar dari TQS itu tersendiri.

\section{B. Total Quality Service (TQS)}

Kotler (1994) mempunyai pandangan bahwa "Jasa ialah segala tindakan atau kegiatan yang dapat ditawarkan oleh suatu pihak kepada pihak lain, yang pada dasarnya tidak berwujud dan tidak berakibat pada kepemilikan apapun. Produksinya bisa dihubungkan atau tidak dihubungkan pada satu produk fisik". Disisi lain (Stanton, 1993) berargumen bahwa Jasa adalah suatu kegiatan yang dapat didefinisikan secara tersendiri yang pada hakkatnya bersifat tidak teraba atau tidak berwujud (intangible) yang merupakan pemenuhan terhadap kebutuhan dan tidak harus terhubung kepada penjualan produk ataupun jasa lain. Jika jasa dapat didefinisikan seperti gambaran diatas maka pengertian dari Total Quality Service (TQS) adalah sebagai sistem manajemen staregik dan juga integratif yang meliputi dan melibatkan seluruh manajer dan karyawan atau atasan dan bawahan, serta mengaplikasikan metode-metode kualitatif maupun kuantitatif untuk memelihara dan memperbaiki dengan berkesinambungan proses-proses organisasi, agar dapat memenuhi atau bahkan 
melebihi ekspektasi, kebutuhan, keinginan, dan harapan pelanggan.

Ada 4 fokus utama Total Quality Service (TQS):

1. Fokus kepada pelanggan (Customer Focus)

Memaksimalkan dan mengoptimalkan identifikasi permintaan pelanggan dan juga membentuk konsep atau desain jasa tertentu bagi paara konsumen. Dalam mengidentifikasi kebutuhan dapat mengembangkan sistem partnership dengan konsumen maupun suplier dengan mendasarkan pada asas mutualisme (saling menguntungkan) diantara kedua belah pihak.

2. Keterlibatan total (Total Involvement)

Keterlibatan total ini berarti komitmen. Harus memberi kesempatan untuk perbaikan pelayanan pada segenap karyawan dan manajemen untuk menunjukkan kualitas kepemimpinan di semua organisasi. Manajemen harus mewakilkan tanggung jawab dan wewenang untuk meningkatkan proses dan etos kerja bagi mereka yang benarbenar bekerja dengan sungguh-sungguh.

3. Pengukuran (measurement), pengukuran internal/eksternal terhadap organisasi dan pelanggan meliputi: 1) Pengukuran dan pengembangan proses dan hasil, 2) Identifikasi output dari proses pekerjaan yang penting sesuai dengan persyaratan pelanggan dan 3) Mengoreksi dan memperbaiki sendiri ketika terjadi kesalahan dalam pekerjaan, tanpa harus menunggu petunjuk dari level yang lebih tinggi. 
4. Dukungan sistematik (systematic support), manajemen bertanggungjawab untuk membangun infrastruktur kualitas ke dalam struktur manajemen internal dan menghubungkan kualitas Jasa berbeda dengan barang, kalau barang merupakan suatu obyek, alat atau benda, sedangkan jasa adalah suatu perbuatan, kinerja, atau usaha. Jasa bersifat intangible, artinya tidak dapat dilihat, dirasa, diraba, dicium, atau didengar sebelum dibeli.

Jasa memiliki empat karakteristik; 1. Intangibility (Jasa berbeda dengan barang, kalau barang adalah berupa objek, alat ataupun benda sedangkan jasa adalah performance atau kinerja, 2. Inseparability (pada umumnya barang biasanya diproduksi, dijual lau dikonsumsi. Sedangkan jasa dijual, diproduksi lalu dikonsumsi, 3. Varability (Jasa memiliki banyak bentuk, variabel, kualitas dan jenis tergantung pada kapan, dimana dan kepada siapa), 4. Perishability (Jasa merupakan hal yang tidak tahan lama atau bersifat dinamis dan tidak dapat disimpan).

\section{Fokus pada Kepuasan Pelanggan Instansi pendidikaan}

1. Identifikasi Pelanggan dan Kebutuhan Instansi pendidikaan

Pelanggan atau konsumtor adalah orang yang menuntut kita atau perusahaan agar memenuhi ekspektasi dan kualitas tertentu, karena hal itu akan berpengaruh pada Performance organisasi atau instansi kita.

L.I.Bean, Freeport, Maine, memaparkan beberapa definisi mengenai pelanggan, yaitu : 
a. Pelanggan adalah orang yang tidak bergantung pada kita, namun kita yang bergantung padanya.

b. Pelanggan adalah orang yang mengajak kita kepada keinginannya.

c. Tidak ada seorangpun yang akan menang ketika berargumentsi dengan yang namanya pelanggan.

d. Pelanggan adalah orang yang sangat penting dan perlu ataupun harus dipuaskan keinginannya.

Agar kepuasan pelanggan teercapai dan terpenuhi, maka kita harus melakukan identifikasi. Mengidentifikasi pelanggan Instansi pendidikaan akan kebutuhan mereka merupakan aspek krusial, karena hal ini menyangkut pada kepuasan pelanggan. Lewis \& Smith mengajukan kerangka identifikasi pelanggan yang ditinjau dari tiga perspektif, yaitu; 1. pelanggan internal (administrasi dan akademik), 2. pelanggan eksternal langsung, 3. pelanggan eksternal tidak langsung.

Pelanggan internal akademik mencakup Siswa/Mahasiswa, staf pengajar, program dan devisi dalam program akademik suatu lembaga atau instansi yang mempengaruhi kepada program tertentu. Sedangkan untuk pelanggan internal administrasi meliputi Siswa/Mahasiswa, karyawan, dan unit, departemen atau divisi yang mempengaruhi suatu pelayanan atau aktivitas.

Adapun Pelanggan eksternal langsung terdiri atas employers, Siswa/Mahasiswa, dan Instansi pendidikaan lain yang menjadi penerima Siswa/Mahasiswa (untuk keperluan 
studi lanjut) dan jasa Instansi pendidikaan tertentu. Sedangkan pelanggan eksternal tidak langsung mencakup legislature bodies, masyarakat, alumni, dan penyumbang atau donatur, yang mempengaruhi keputusan dan proses berjalannya suatu lembaga atau Instansi pendidikaan. Perhatian dan fokus utama pada pelanggan-pelanggan ini harus diprioritaskan dan diutamakan berdasarkan urutannya, karena pelanggan internal dan pelanggan eksternal langsung adalah orang pertama yang menerima pelayananan yang berkualitas dari suatu Instansi pendidikaan. Disisi lain pelanggan eksternal tidak langsung juga harus diperhatikan dengan baik, karena merekalah yang memiliki pengaruh dan andil besar dalam bidang finansial dan akreditasi.

2. Hakikat Hubungan Pelanggan dan Pelayan Instansi

Pendidikaan

Istilah Tenaga Pendidik, Siswa/Mahasiswa, dan lainlain tak perlu diganti dengan pelanggan. Yang perlu dipahami adalah makna dan nilai hakiki pelanggan. Ada hubungan tertentu, khususnya hubungan kemanusiaan, antara Instansi pendidikaan dan para pelanggannya. Ada kebutuhan pelanggan, dan Instansi Pendidikan harus berusaha memahami serta memenuhinya. Sebaliknya pelanggan mempunyai kewajiban-kewajiban tertentu terhadap Instansi terkait. Nilai hubungan itu antara lain:

a. Saling membutuhkan, contohnya Tenaga Pendidik memerlukan Siswa/Mahasiswa karena tanpa 
Siswa/Mahasiswa Tenaga Pendidik tidak akan ada, begitu juga sebaliknya.

b. Saling memahami, contohnya Instansi pendidikaan memahami kebutuhan Siswa/Mahasiswa akan dunia kerja, maka harus meningkatkan mutu,dan Siswa/Mahasiswa juga harus giat belajar untuk hasil yang bagus.

c. Saling melayani dengan baik. Contohnya, menaikkan grid pangjat jabatan yang etos kerjanya bagus, sehingga nanti akan muncul kinerja yang baik dan berprestasi.

d. Kebersamaan, contohnya melakukan segala proses dalam pendidikan di instansi pendidikan dengan bersama-sama.

Keempat nilai itu bisa berjalan dan bergerak progresif apabila pelayanan bermutu telah tumbuh dan berkembang. Keempat nilai itu adalah nilai kependidikan tinggi, bahkan nilai kependidikan umumnya, yang sangat mendasar. Dikatakan sangat mendasar karena sangat dibutuhkan dalam kehidupan berbangsa dan bernegara. Keempat nilai-nilai itu harus ditumbuhkembangkan dalam diri setiap orang, terutama Siswa/Mahasiswa sebagai pelanggan primer, melalui proses melayani-dilayani dalam semua kegiatan.

4. Mengelola Kualitas Jasa

Cara utama mendiferensiasikan sebuah perusahaan jasa atau dalam hal ini Instansi pendidikaan adalah memberikan jasa yang lebih mempuni dan berkualitas 
dibanding para pesaing secara konsisten. Kuncinya aadalah dengan upaya memenuhi atau bahkan melebihi ekspektasi kualitas jasa pelanggan sebagai sasarannya. Untuk dapat mengetahuinya berikut akan diuraikan atribut untuk mengelola kualitas jasa mengenai dimensi kualitas jasa (pelayanan), model kualitas jasa (pelayanan), persepsi pelanggan terhadap jasa, dan ekspektasi pelanggan kepada jasa itu tersendiri.

Bila beberapa dimensi tersebut diejawentahkan pada perusahaan manufaktur, maka berdasar penilitian Parasutaman dkk. (1985) tentang kualitas jasa dan juga faktor-faktor yang mendorongnya. Mereka mengemukakan 5 dimensi kualitas untuk mengevaluasi kualitas jasa :

a. Reliability (keandalan), adalah kemampuan memberikan pelayanan dengan sigap dan mampu memuaskan.

b. Responsiveness (daya tanggap), adalah kehandalan dalam memberikan pelayanan jasa dengan tanggap.

c. Assurance (jaminan), yakni kemampuan menghadirkan rasa aman dan tanpa bahaya kepada para pelanggan.

d. Empathy, yakni, kemampuan dalam melakukan hubungan yang baik dengan pelanggan dan juga bisa berkomunikasi dengan baik.

d. Tangibles (bukti langsung), yakni fasilitas fisik, perlengkapan, pegawai dan sarana komunikasi. 
Hasil penelitiannya menyimpulkan bahwa reliability adalah faktor terpenting dalam menetukan kepuasan pelanggan. Kelima dimensi tersebut lebih akrab dikenal dengan istilah SERVQUAL. Sehingga penilitian meereka juga mendorong timbulnya penelitian yang senada dengan dibumikannya pada berbagai instansi.

\section{Prinsip Dasar Kepuasan Pelanggan}

Karena fokus kualitas adalah mengenai kepuasan pelanggan, maka perlu juga dipahami mengenai komponenkomponen yang berhubungan dengan kepuasan pelanggan itu sendiri. Walaupun pada dassarnya secara sederhana kepuasan pelanggan adalah keadaan dimana harapan, kebutuhan dan keinginan dapat terpenuhi.

Karena kepuasan pelanggan tergantung bagaimana ekspektasi dan persepsi mereka. Sehingga kita sebagai pemasok layanan jasa tersebut juga harus mengetahui faktorfaktor yang mempengaruhi ekspektasi dan persepsi mereka. Adapun faktor-faktor tersebut meliputi :

a. Kebutuhan dan kenginan yang mereka rasakan pada saat transaksi langsung dengan produsen atau penyedia layanan. Jika kebutuhan dan keinginannya besar maka ekspektasi mereka terhadup produk juga besar, begitu pula sebaliknya.

b. Pengalaman yang pernah dirasakan ketika mengkonsumsi produk dari para perusahaan pesaingnya. 
c. Pengalaman dari lingkungan bergaul, sehingga mereka juga dapat terpengaruh dari cerita pengalaman temanteman mereka dalm mengkonsumsi produk tertentu.

d. Komunikasi melalui iklan dan pemasaran yang sesuai dengan ekspektasi pelanggan, dengan kata lain tidak melebih-lebihi dari batas ekspektasi pelanggan itu tersendiri.

\section{Kualitas Pelayanan Prima (Quality Service Excellence) Dalam Pandangan Islam.}

Islam sebagai agama yang Universal dan komprehensif. Universal berarti bahwa Islam diturunkan bagi seluruh makhluk di muka bumi dari berbagai lapisan dan berbagai masa. Sedangkan komprehensif bahwasanya Islam memiliki ajaran yang lengkap dan sempurna.

Kesempurnaan ajarannya yang dapat mengatur seluruh aspek kehidupan manusia, tidak hanya aspek spiritual akan tetapi juga aspek muamalah yang meliputi sosial, politik, hukum dan ekonomi yang sangat kompleks penuh dengan orang-orang yang menjual, membeli, menawarkan, berinvestasi dan lain-lain. Serta meliputi perkara-perkara pidana maupun perdata. Hal ini merupakan salah satu tahaptahap dalam membangun suatu usaha.

Al-Quran sebagai pedoman dan petunjuk bagi umat islam juga tak terlepas menjelaskan dan mengidentifikasi permasalahan akidah, syari'ah dan akhlaq. Dalam konteks 
ini TQS sebagai salah satu bentuk pekerjaan atau 'amaliyah hadits menjelaskan bahwa :

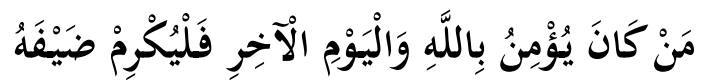

"barang siapa yang beriman kepada Allah dan hari akhir, maka muliakanlah tamunya”(Muttaffaq ‘alihi)

Dan termaksud manhaj shahabat dan para salafus shalih adalah berakhlaq mulia dan memuliakan tamu, Allah Azza wa Jalla berfirman dalam surat Al-Hasr : 9 :

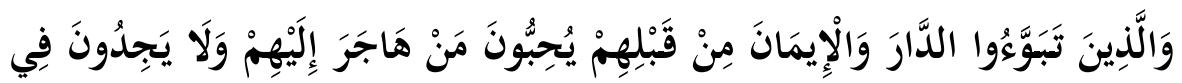

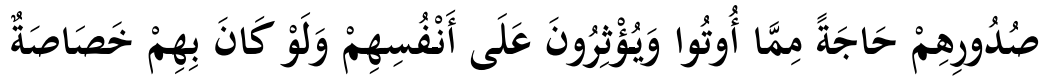

"Dan orang-orang (Anshor) yang telah menempati kota madinah dan beriman sebelum kedatangan mereka (muhajirin), mereka menciantai orang yang berhijrah ketempat mereka dan mereka tidak menaruh keinginan dalam hati mereka terhadap apa yang diberikan kepada mereka (muhajirin) dan mereka mengutamakan (muhajirin) atas diri mereka sendiri, meskipun mereka juga sangat butuh.”.

Disebutkan bahwasanya ayat ini sebab pada saat itu kau Anshor lebih mengutamakan keperluan makanan tamunya dari para kafilah muhajirin. 
Secara lebih mendalam ayat-ayat Al-Qur'an tersebut bahwasanya memuliakan tamu adalah akhlaq yang diajarkan Rasulullah dan para sahabatnya dan juga nabi-nabi terdahulu :

Allah berfirman dalam surat Ad-Dzaariyaat : 24-27 :

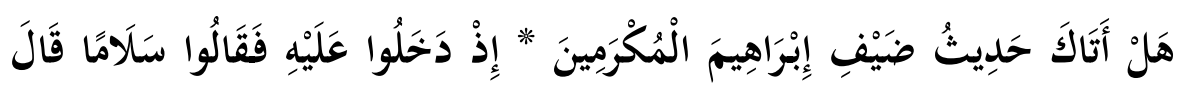

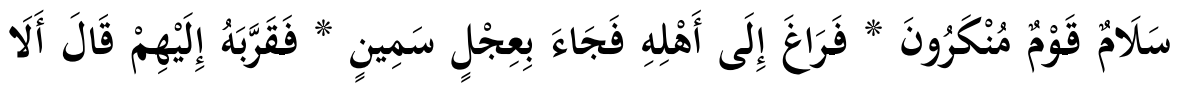 * تَأْكُلْونَ}

"Sudahkah sampai kepadamu cerita tamu ibrahim yang dimuliakan (malaikat) ketika mereka masuk kepadanya, lalu mengucapakan salam, ibrahim menjawab "Salam" (Mereka itu) orang-orang yang belum dikenalnya * maka diam-diam dia (ibrahim) pergi menemui keluarganya, kemudian dibawahnya daging anak sapi yang gemuk (yang dibakar) * lalu didekatkanlah (hidangan) itu kepada mereka, ibrahim berkata "mengapa kamu tidak memakannya!".

Konklusinya adalah, bahwa Islam sendiri sangat memandang penting bagaimana cara melayani dan menghormati tamu, sehingga seyogyanya bagi para pelaksana dan pemerhati pendidikan untuk mengedepankan kepuasan tamu/pelanggan pendidikan dan juga sebagai salah satu bentuk membangun progresifitas sekolah. 


\section{DAFTAR PUSTAKA}

Tjiptono, Fandy, Prinsip-Prinsip Total Quality Service (TQS), Yogyakarta: Penerbit Andi, 1997

M.N Nasution, Manajemen Mutu Terpadu, (Total Quality Management), Jakarta: Ghalia Indonesia, 2001

Gaspersz Vincent, "Total Quality Management", cet. II Jakarta: Gramedia Pustaka Utama, 2002

Lewis, RG \& Smith, D.H, Total Quality in Higher Education, Florida:

St.Lucie Press 1994

Parasuraman, "Improving Service Quality in America: Lesson learned", Journal of retailing, 1988

Badan Akreditasi Nasional Instansi pendidikaan, Akreditasi Program Studi Jenjang Sarjana (S1) Hasil Penilaian Tahun 1996/1997. Direktorat Umum Departemen Pendidikan dan Kebudayaan.

Umar, Husein, Riset Pemasaran dan Perilaku Konsumen, Jakarta:Gramedia, 2002

Dr. H. Hasan Baharun, M.Pd., \& Dr. Zamroni, M.Pd.,MANAJEMEN MUTU PENDIDIKAN Ikhtiar dalam Meningkatkan Mutu Pendidikan Madrasah melalui Pendekatan Balanced Scorecard, Tulungagung: Akademia Pustaka,2017 



